\title{
Self-motion as other-motion in Aristotle's Physics
}

\author{
Ursula Coope
}

In Physics viri.5, Aristotle sets out to provide a positive account of selfmotion. He characterises self-motion as a kind of other-motion: a selfmover must be composed of two parts, one of which moves the other. The part that produces the movement is a kind of unmoved mover, in that it produces motion in a way that does not depend on it itself being moved. The contrast here is with a moved mover, something that produces motion just because it itself is moved by something else, as one carriage of a train might move another just because it in its turn is moved by the engine.

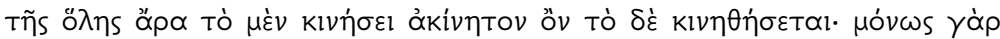

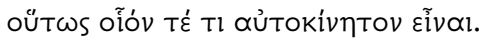

In the whole thing, there is [a] that which imparts motion without itself being moved and $[\mathrm{b}]$ that which is moved, for only in this way is it possible for a thing to be self-moved. $(258 \mathrm{a} 2-4)$

In this chapter, I shall discuss three questions raised by this account of selfmotion. The first relates to the role of this account in Physics viII. Aristotle's overarching aim here is to argue that there must be some first moved thing that is continuously in motion, and that its motion must be caused by an ultimate primary mover that is absolutely unmoved. Why is an account of self-motion given such a prominent place in this argument? After all, in Metaphysics L Aristotle argues for the existence of an unmoved mover without appealing in the same way to an account of self-motion. ${ }^{\mathrm{I}}$

\footnotetext{
I In On the Movement of Animals I-IV, Aristotle argues that a self-mover must have, both within and outside itself, a kind of unmoved springboard that it pushes against when it moves itself. He goes on to ask whether the universe also moves itself in this way, by pushing back against something that is unmoved, and he argues at length that it does not: there is nothing that could serve as such a springboard for the whole universe. Note, though, that the possibility considered in these chapters of On the Movement of Animals is rather different from that discussed in Physics viri. In Physics viri, Aristotle argues that within a self-mover there must be an unmoved mover. In On the Movement of Animals, neither the internal nor the external unmoved thing is described as a mover. It is, rather, a
} 
My second question concerns Aristotle's central argument that a selfmover must contain within it a kind of unmoved mover. One obvious opponent here is Plato, who, like Aristotle, thought that a chain of moved movers must have its origin in a self-mover, but who described selfmovement as a kind of self-moving motion. Does Aristotle have any argument against this Platonic view that the ultimate origin of a chain of moved movers must be something that is itself in motion?

In the third section of my chapter, I consider an obvious objection that might be made to Aristotle's account of self-motion: can such an account really distinguish between a genuine self-mover (a unified thing, one part of which moves another) and two distinct things, one of which moves the other? For instance, can Aristotle avoid the consequence that when an animal moves a stick, the animal plus stick counts as a self-mover? Aristotle needs to have something to say in answer to this question if his account is really to be an account of self-motion, rather than an argument that there is, in the end, no such thing as self-motion.

As we shall see, the first of my questions bears on the other two. Once we understand the purpose for which Aristotle is giving this account of selfmotion, we can see what constraints he is under in giving it, and which of the possible objections to it he most needs to answer.

\section{The role of the Physics viII.5 account of self-movement in Aristotle's discussion}

At this point in Physics vin, Aristotle has already made the following claims:

(i) There always has been and always will be movement (virI.I-2).

(ii) Every moving thing must be moved by something (virI.4).

(iii) A chain of movers moved by other things cannot go on to infinity: it must have an origin (viII.5, 256a4-b3).

From (ii) and (iii), he concludes:

(iv) The origin of a chain of moved movers must either be a self-mover or an unmoved mover (viII.5, 257a26-27).

He then gives his account of self-motion, arguing that:

kind of springboard: something that the animal pushes against in moving itself. (For discussion, see the chapters by Coope and Morison, in Primavesi and Rapp (in press).) 
(v) A self-mover must be a composite, one part of which moves without itself being moved, the other part of which is moved (viII.5, 257a3I258b9).

He goes on to argue that:

(vi) There must be some first, continuous, eternal, and uniform circular locomotion. (The continued coming to be of animal self-movers depends on this.) (viri.6, 258bi6-259a6, 259ai3-20)

(vii) There must be some single cause of this primary motion. (viII.6, 259a6-20)

(viii) The unmoved mover within an animal self-mover is accidentally moved when the animal moves. An unmoved mover that is accidentally moved by itself in this way could not produce infinite continuous motion, and hence could not be the unmoved mover that explains this primary motion. (vili.6, 259b20-26oaio)

(ix) In fact, the cause of the primary motion must be something that is itself absolutely unmoved. (viII.6, 259b22-3I) ${ }^{2}$

My question is about the role, in this argument, of (v), the claim that a selfmover is composed of an unmoved mover and the thing it moves. An interesting feature of the argument I have set out above is that this claim seems somewhat tangential. In (iv), Aristotle sets out two alternatives: the mover that originates a chain of moved movers must be either a self-mover or an unmoved mover. However, what he goes on to say (in (viii) and (ix)) seems to rule out the possibility that what causes the primary continuous locomotion could be a self-mover, for he claims that the cause of this motion must be a mover that is absolutely unmoved. A mover that is absolutely unmoved cannot in any sense 'belong to' the thing it moves, since, according to Aristotle, a mover counts as (at least) accidentally moved if it belongs to a thing that is moved (or contains such a thing as a part) (254b9-10). This seems to imply that an absolutely unmoved mover cannot, together with what it moves, constitute a unified whole that counts as a self-mover. Hence, the origin of the ultimate primary continuous motion must be an unmoved mover rather than a self-mover. ${ }^{3}$ Given this,

\footnotetext{
2 Aristotle allows that certain heavenly bodies can be accidentally moved by something and yet moved continuously (as he must, if he is to maintain, as he does elsewhere, that the spheres on which the planets are set are accidentally moved by outer spheres), but he claims that something that accidentally moves itself cannot cause continuous motion (259b29-3I).

${ }^{3}$ Further grounds for this conclusion can be found in the features Aristotle ascribes to self-movers in Physics VIII.4, when he is arguing that the simple bodies are not self-movers. He says there that selfmovement is peculiar to living things and that what can move itself can stop itself (255a6-9).
} 
Aristotle's attempt to establish the precise nature of self-movers can seem something of a digression.

Why, then, does Aristotle devote the second half of Physics viII.5 to giving this account of self-motion? There are, I think, two main reasons why this account is important to Aristotle's overall argument. Both of them have to do with Aristotle's response to Plato.

In Laws x, Plato argued that the ultimate cause of motion was a selfmotion (understood as a self-causing movement). Aristotle could have responded to this simply by claiming that such a cause would not be able to produce eternal continuous motion, but in fact he has a more radical objection. He argues that no origin of movement could be a self-causing movement, and hence that Plato's account is mistaken even as an account of self-motion. This argument is important not simply as a way of responding to Plato, but also because it provides crucial support for one of Aristotle's more positive claims. In particular, I shall argue, it is by understanding what is wrong with Plato's account of self-motion that we come to see why it is that every thing in motion must be moved by something (see section II below). This, then, is the first reason why Aristotle's positive account of self-motion is more than a digression: the argument he gives here against Plato provides further justification for his claim (ii): the claim that every moving thing must be moved by something.

However, I suspect that Aristotle also has a second reason for discussing self-motion more fully here. He wants to say that there is, after all, something right in Plato's claim about the primacy of self-motion (even though Plato had the wrong account of self-motion). An animal self-mover is a first mover: it (or more precisely, the mover within it) is the origin of a chain of moved movers. Aristotle wants to emphasise what animal self-movers have in common with the first mover of the primary eternal motion. ${ }^{4}$ As we have

\footnotetext{
Moreover, the fact that each of the simple bodies only moves naturally in one direction shows that such movement cannot be self-movement (255a9-II). For an alternative interpretation, on which the first eternal movement of Physics VII is a kind of self-movement, see Kosman 1994. Although I think Kosman is right to stress that the first eternal movement together with its mover constitutes something that is in many respects like a self-mover, the possibility that it is strictly speaking a self-mover is, I think, ruled out by Aristotle's claim that the first mover is not even accidentally moved, together with his account (in Physics viri.4) of what it is to be accidentally moved.

4 This perhaps explains why, even though he does not think that the eternal first motion is, strictly speaking, self-motion, he is nevertheless prepared to say that what moves itself is 'the principle (archê) of moved movers and the primary thing among things that are moved' (26ra25-26, cf. similar remarks at Physics viıi.6, 259a33-bi and at MA I, 698a7-8). What moves itself is primary among sublunary things that are moved, and the account he has given of the way in which a self-mover moves itself applies also to the way in which the eternal first movement is caused by its mover. That is why the fact that self-motion is a kind of locomotion is a reason for thinking that the eternal first motion will also be locomotion (26ra23-26).
} 
seen, this primary eternal motion cannot be a kind of self-motion, since its mover is absolutely unmoved. Nevertheless, I shall argue, Aristotle's account of self-motion in Physics viII.5 is framed in such a way that it applies not only to genuine self-movers, but also to the conjunction of the first eternal moved thing and its unmoved mover. As such, it aims to give necessary but not sufficient conditions for being a self-mover. In this account, Aristotle includes only those features of self-movers that are also features of a particular conjunction of things that does not constitute a selfmover: the first eternal moved thing together with its mover.

This raises an obvious question. If Aristotle does not in fact think that the combination of the first eternal moved thing and its mover constitutes a self-mover, then why does he go to such pains to formulate an account in Physics viII.5 that applies not only to genuine self-movers but also to this combination of the first eternal moved thing and its mover?

One possible answer is that providing such an account helps to establish something about the unity of the science of physics. In Physics II.7, Aristotle says that there are three different realms of study: one concerned with that which cannot undergo movement, a second concerned with eternal moving things, and a third concerned with perishable moving things (198330-3I). The study of things that cannot undergo movement is, he says, no part of physics (198a28). What, though, of the other two realms of study? Elsewhere, he implies that physics is a science concerned with both eternal and perishable moving things. ${ }^{5}$ This raises a question: what justifies the assumption that there is one science of both eternal and perishable moving things, and that the same basic principles apply to both eternal and time-limited movement? In Physics viII, this question arises with particular urgency, since Aristotle will argue that the mover that produces the primary eternal motion is itself absolutely unmoved (and hence, according to his own earlier remark (198a28), falls outside the scope of physics). Can a single science concern itself both with movement that is produced in this way and also with the kind of movement that has its origin in animal self-movers?

To answer this, it is not enough to show that (as Aristotle argues in Physics vini.6) animal self-movers are causally dependent on things that are in eternal motion. Aristotle clearly thinks that $\mathrm{X}$ can be causally dependent on $\mathrm{Y}$, even though $\mathrm{X}$ and $\mathrm{Y}$ do not fall under the same science. ${ }^{6}$ What is

5 See, in particular, Metaph. L.I, Io69a36-b2. For an illuminating discussion of Aristotle's views on the unity of physics, see Falcon 2005 .

${ }^{6}$ As we have just seen, eternal motion is causally dependent on an absolutely unmoved mover, although such a mover does not fall within the scope of physics. 
needed is an abstract account that will bring out the similarities between self-movers, on the one hand, and the first eternally moved thing together with its mover, on the other. It is precisely such an account, I argue, that Aristotle provides in the second half of Physics viII.5. Because it applies both to animal self-movers and also to the primary eternally moved thing together with its mover, this account helps to justify the assumption that physics is a unified science.

I have argued that Aristotle provides the account of self-motion in Physics VIII.5 partly as a reply to Plato and partly as a way of emphasising what genuine self-movers have in common with the primary eternal moved thing together with its mover. In what follows, I first ask how Aristotle's argument fares as a response to Plato, and then discuss how the content of his account is affected by his wish to capture just those features of selfmovers that they share with the first moved thing together with its mover.

\section{The argument that a self-mover must be composed of two parts: An unmoved mover and what it moves}

I have claimed that Aristotle's account of self-movers here is written partly in opposition to Plato's view in the Laws, according to which the ultimate origin of a chain of moved movers is a self-causing movement. In this section, I shall ask whether Aristotle has any good argument against this Platonic view.

The core of Aristotle's argument comes in a single paragraph at 257a3Ibi3. First (257b2-6), he says that it is impossible that what moves itself should as a whole (and while remaining one and indivisible in form) both cause and undergo the same movement. This impossibility is illustrated with two examples: the same thing cannot at the same time and in the same respect be teaching and being taught; the same thing cannot at the same time and in the same respect be becoming healthy and producing health. Second (257b6-I3), he says that what undergoes movement must be in potentiality whereas what causes movement must already be in activity

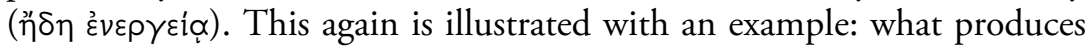
heat must itself be hot. From this, it follows that what produces heat must be distinct from what is becoming hot (since what is becoming hot must not yet be hot). ${ }^{7}$ Aristotle then generalises from this example: 'so too in

\footnotetext{
7 'It is that which is hot that produces heat, and in general that which produces the form possesses it. Consequently [if the mover is not distinct from the moved] the same thing in respect of the same

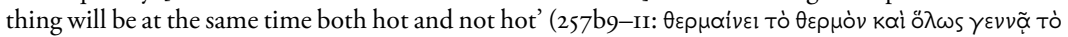

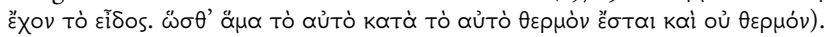


every case where the mover must have a synonymous property'. From this he concludes, quite generally, that what first produces a movement must be distinct from what undergoes that movement.

Much of this passage simply relies on examples. As interpreters, we need to ask how Aristotle means to use these examples to defend his general conclusion about self-motion. After all, his aim is not merely to show that in certain cases the primary origin of a movement is something unchanging. Although this would establish (against Plato) that it is possible for the ultimate origin of a movement to be something that is not undergoing movement, it would not establish Aristotle's conclusion that within a selfmover there must be a part that is moved and a distinct, unmoved, part that is the mover.

Aristotle's final example (that the cause of becoming hot must be something that is already hot) suggests the following general argument:

(i) The primary cause of something's changing towards being $F$ must be something that is itself already $\mathrm{F}$.

(ii) What is undergoing a change towards being $\mathrm{F}$ cannot yet be F.

(iii) Nothing can at the same time and in the same respect both be F and not be F.

So: (iv) The primary cause of something's changing towards being $\mathrm{F}$ must be distinct from what undergoes the change towards being $\mathrm{F}$.

So: (v) Since the mover within a self-mover is the primary cause (not merely an instrumental cause) of the self-mover's movement, the part of the self-mover that produces movement must be distinct from the part that undergoes that movement.

However, if this is Aristotle's argument, it seems to face two insuperable problems, both related to premise (i), the claim that a change towards being $\mathrm{F}$ must be caused by something that is already $\mathrm{F}$. The first problem is that the scope of premise (i) is too restricted for it to do the work needed of it in this argument. Aristotle himself recognizes that (i) only holds for a certain range of cases, and, because of this, the conclusion he draws is carefully qualified: 'So too in every other case in which the mover must have the synonymous property' (257bir-I2). This simply invites the question: what about those cases in which the mover doesn't have to have the synonymous property? How could Aristotle go from this carefully restricted conclusion to the general claim that, within a self-mover, what is moved must be distinct from the mover? These questions are especially pressing, since it is hard to see how premise (i) could apply to a particularly 
central kind of movement: locomotion. Locomotion is not naturally thought of as the acquisition of a form, and there is no obvious sense in which the agent of a locomotion must already be in the state that the moving thing is progressing towards. After all, it is clearly not true that what moves something to place P must itself already be in place $\mathrm{P} .{ }^{8}$ But Aristotle's argument needs to apply to locomotion, since he himself goes on to say that locomotion is the primary motion and that, in the strictest sense, the movement with which a thing moves itself is locomotion (253ai4-I5, 26ra23-25).

Of course, there may be a priori grounds for accepting something like premise (i), in spite of the apparent counterexamples. However, when we consider what such a priori grounds might be we encounter a second problem. A plausible suggestion is that premise (i) is based on what might be called the 'transmission' principle of causation: the principle that what ultimately causes a thing to be a certain way must itself be that way. If causation is thought of as a kind of transmission of a property from one thing to another, then it is easy to see how this principle might be justified: how could an agent transmit a property to something else if it didn't itself have that property?' The problem with this is that one could accept this general principle without accepting Aristotle's application of it, and hence without accepting premise (i). In fact, one could use this same principle to argue for the very view Aristotle is attacking: the Platonic view that what causes motion must itself be in motion. The argument would go as follows. We are trying to explain X's motion. We have already agreed that if $\mathrm{X}$ is in motion, it must be being moved by something. But how can the mover transmit movement to X unless it is itself in movement?

Indeed, something like this view seems to lie behind Plato's reasoning in the Laws. Plato agrees that every movement has a cause and that chains of moved movers must have their origin in some primary cause. But he concludes that the primary cause is a self-moving movement. Plausibly, the basis for this view is this alternative application of the transmission principle: he assumes that what causes movement must itself be in movement. So, if we accept the transmission principle (the idea that what

\footnotetext{
${ }^{8}$ Of course, there are various ways in which one could try to fit locomotion into the model. For instance, one might say that the agent of locomotion has in its mind the goal towards which the locomotion is proceeding (as the craftsman has in his mind the form of the thing he is producing). But this would not be enough to save the apparent argument, since it is, at least prima facie, possible for one and the same thing (at the same time) both to have the goal $\mathrm{F}$ in mind and also to be (at) F.

9 Waterlow 1982: 244-246 calls this the model of 'giving and receiving'.
} 
ultimately causes a thing to be a certain way must itself be that way), there are two rival conclusions we might draw. We might conclude (with Plato) that what causes a thing to be in movement must itself be in movement (only then can it transmit movement to the thing it acts upon), or we might conclude (with Aristotle) that what causes a thing to become F must itself be $\mathrm{F}$ (only then can it transmit F-ness to the thing it acts upon). The transmission principle by itself cannot justify the Aristotelian, as opposed to the Platonic, conclusion.

The fact that this argument is vulnerable to these objections should make one doubt whether it is, in fact, the argument Aristotle had in mind. I shall argue that, in fact, Aristotle is defending here a more abstract principle: that what first causes motion must do so in virtue of being a certain way, not in virtue of itself undergoing motion. When Aristotle says that, in certain cases, the cause of becoming $F$ is something that already is $F$ he is providing an illustration of this more abstract principle, but he is not meaning to imply that all first causes operate by transmitting a form to the thing upon which they act. ${ }^{\mathrm{IO}}$ His argument, thus, does not rely on the principle of contradiction, in the way that his remarks about the hot thing might suggest: he is not saying that the first cause must already be F, whereas what becomes F cannot yet be F. Instead, his point is that the first cause is a cause in virtue of stably being a certain way, not in virtue of changing or becoming. The sense in which a self-mover must be composite is, then, that it must have two aspects: qua mover it is unchanging (since it produces movement in virtue of stably being a certain way), whereas qua moved it is undergoing change. If this is Aristotle's argument, then his objection to Plato is that, on Plato's view, the ultimate explanation of a movement is itself a movement, rather than a state of being.

If this is right, then we need to ask how Aristotle would justify the claim that the ultimate explanation of movement must be a thing's stably being a certain way. I shall argue that Aristotle provides such a justification in a few difficult lines in our passage. In these lines, he draws a connection between movement, incompleteness, and potentiality:

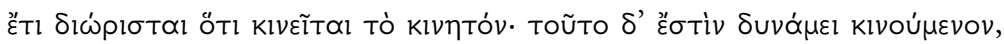

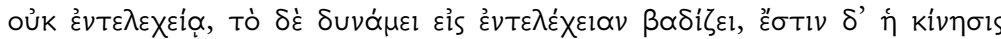

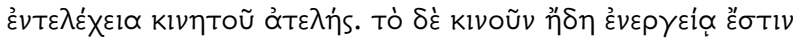

Further, it has been established that the moveable is what is moved. But this is moved in virtue of potentiality, not fulfilment. But what is in virtue of

ro Or at least, the argument he gives does not rest on the truth of this universal claim. 
potentiality progresses towards fulfilment, and movement is the incomplete fulfilment of the movable. But the mover is already in activity. (257b6-9)

The difficulty of these lines stems partly from a problem of translation. The

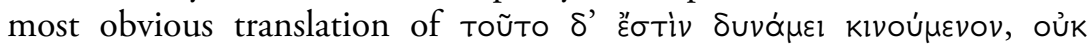

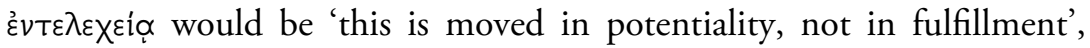
but this translation seems to get the wrong sense. When the movable thing is being moved, it is not merely potentially being moved. I have, instead, given the translation: 'it is moved in virtue of potentiality, not fulfilment'. ${ }^{\text {II }}$ To understand what might be meant by saying this, we shall need to look at what Aristotle says elsewhere about the relation between movement and potentiality.

The argument in these lines rests, I think, on two claims: first, the claim that what is in potentiality is posterior to, and causally dependent on, what is in fulfilment ("what is in virtue of potentiality progresses towards fulfilment'); and second, the claim that a moving thing is, as such, not completely in fulfilment ('movement is the incomplete fulfilment of the movable'). Before we consider how Aristotle is putting these two claims together in this argument, it will be helpful to look at each of them in turn.

The first claim is not directly about movement at all. It is, rather, about the relation between what is in fulfilment and what is in potentiality. Aristotle says that what is in fulfilment is prior, in a certain way, to what is in potentiality. In our passage, he expresses this priority relation by saying that what is in potentiality 'progresses towards' (badizei eis) fulfilment. With this notion of 'progressing towards' he means, I think, to capture a kind of teleological relation. Being potentially is a way of being for the sake of some fulfilment. Aristotle spells this point out much more fully in a discussion of potentiality and fulfilment in Metaphysics Theta 8. He says there that what comes to be progresses towards (badizei epi) a principle and end (telos) (I050a7-8). The end is an activity (energeia), and the thing that comes to be acquires its potentiality for the sake of such an activity. Thus, animals have sight (a potential) for the sake of seeing (an activity), and humans have the art of housebuilding (a potential) for the sake of building houses (an activity) (IO5OaIO-I2).

Aristotle takes this fact about teleological directedness to ground a further claim about causation: the primary cause of something that is in potentiality must be something that is in fulfilment. His thought seems to be that anything that is, by its very nature, directed towards (or for the

II In this, I follow Waterlow I982: 244n.27. 
sake of) some further thing must be a dependent kind of entity. It must depend on, and in particular derive its end-directedness from, some distinct cause. Ultimately, the source of such end-directedness must be something that is not similarly end-directed. The primary cause must be something that is just what it is, without reference to anything further. The primary cause must thus be something that is in fulfilment, not in potentiality. He illustrates this with examples of cases in which being potentially $F$ is explained by being $F$ in fulfilment. To be an acorn is to be potentially an oak. An acorn must, then, have as its primary cause something that is, not merely potentially but in fulfilment, an oak. To be a fluteplayer is to have the potential to play the flute; the primary cause of being a fluteplayer must be the activity of playing the flute (one becomes a fluteplayer by practising). ${ }^{\text {I2 }}$

This tells us that being $F$ in fulfilment is causally prior to being $F$ in potentiality, but it does not, by itself, tell us anything about the relation between causal priority and movement. For this, we need to turn to the second claim Aristotle makes in this passage: the claim that a moving thing is, as such, not completely in fulfilment. In making this claim, Aristotle is clearly referring back to his definition of kinêsis in Physics III.

He defines movement/change (kinêsis) there as 'the fulfilment (entele-

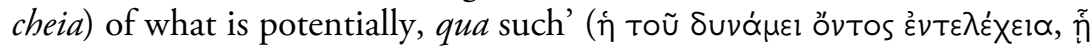
Toloũtov) (2OIa9). What exactly this means is controversial. Interpreters have disagreed over what is meant by entelecheia, over what is meant by 'qua such', and over how to understand the phrase 'what is potentially' (is this what is potentially in some state or what is potentially changing?). ${ }^{13}$ For now, I want to leave these disputes to one side and instead look directly at something Aristotle presents as an advantage of this definition. He says that this definition allows us to capture what was right about earlier, confused, accounts of movement: accounts which represented change/movement as inequality, difference, or non-being. Such accounts were confused, in that they failed to provide necessary and sufficient conditions for movement (something can, for instance, be different without moving). But these accounts nevertheless correctly recognised something about the nature of movement: namely, that movement is essentially privative, or as Aristotle puts it, incomplete.

${ }^{12}$ See Metaphy. Theta 8, IO49b24-32. Aristotle draws the conclusion that the mover is already in activity at I049b27, using almost exactly the same wording as at Phys. viII.5, $257 \mathrm{~b} 9$.

${ }^{13}$ For some contrasting answers to these questions, see Kosman 1969, Heinaman 1994, Kostman 1987, and A. Agnastopoulos 20Io. I discuss the first three of these interpretations in Coope 2009. 
We can learn something about what Aristotle means by this if we look at the reason he gives for thinking that movement is incomplete:

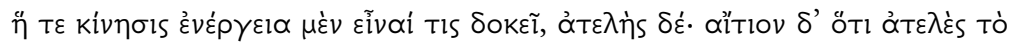

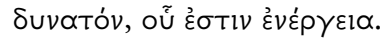

Movement is thought to be activity of a kind, but incomplete. The cause is that the potential thing of which it is an activity is incomplete. $(20 \mathrm{Ib} 3 \mathrm{I}-33)^{\mathrm{I4}}$

Movement is incomplete, Aristotle says, because the corresponding dunaton (or potential thing) is incomplete. This explanation is, at first sight, puzzling. Given Aristotle's general views about the priority of fulfilment (or actuality) to potentiality, one would expect features of what is capable of phi-ing to be explained by features of phi-ing, rather than vice versa. How, then, can Aristotle maintain that the incompleteness of movement is explained by the incompleteness of the corresponding potential thing?

Aristotle is, I think, claiming that movement is related in a special way to the corresponding potentiality. This follows from his definition of movement as 'the fulfilment of what is potentially, qua such'. Movement is the proper activity of what is potentially, insofar as it is merely in potentiality. Because of this, movement inherits certain features of the potential thing, in a way that other activities do not. Thus, Aristotle is not saying that the potentiality exercised in movement is incomplete and that there is, in contrast, some complete kind of potentiality exercised in the kind of activity that is not movement. Rather, he thinks that all potential things are, as such, incomplete, but that movement is related to potentiality in such a way that it inherits the incompleteness of the corresponding potential thing. ${ }^{15}$ Aristotle is alluding to this special relation of movement to potentiality when he says, in our passage from Physics viII, that the

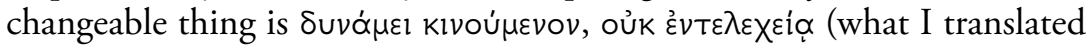
as 'moved in virtue of potentiality, not fulfilment').

To be incomplete (ateles) is to be without an end. As we saw, a potential thing is directed at ('progresses towards') some fulfilment. The potential thing is thus ateles, because it is directed at some end (telos) that is other than it. Aristotle's claim is that movement, because of its connection to potentiality, is similarly end-directed.

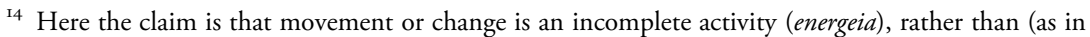
VIII) an incomplete fulfilment (entelecheia), but Aristotle seems to be using the two words interchangeably in these passages, so I think we can take him to be saying the same thing.

is Here I am in agreement with Kosman 20I3: 66, who says, commenting on 20Ib3I-33, 'This cannot mean that there is some special kind of incomplete ability, the realization of which is incomplete and is motion. For all mere ability is incomplete or unperfected - atelês.' 
We are now in a position to arrive at an understanding of our passage by putting together these claims about incompleteness, posteriority, movement, and potentiality. As we saw earlier, Aristotle thinks that because of the way in which potentiality is directed towards fulfilment, a thing that is in potentiality cannot be causally primary. Being potentially $\mathrm{F}$ is an essentially other-directed way of being. Aristotle's point here is that movement also is an other-directed way of being. In this, movement is much like potential being. Just as the potential to be a musician is for the sake of actively being a musician, so also the movement becoming a musician is for the sake of actively being a musician. Just as the seed is for the sake of actively being the mature animal, so also growing (a change) is for the sake of actively being a mature animal. There is reason, then, to think that movement will be posterior to activity, just as we earlier argued that potential being is posterior to active being.

Aristotle holds that as movement inherits its incompleteness (and hence posteriority) from potentiality, so also it inherits its lack of causal primacy. A movement must have as its first cause something that explains its directedness towards an end, something that determines what would count as interference with, or completion of, that movement. What provides this explanation cannot be something that itself stands in need of a similar explanation. Thus, a movement must have its origin in something that is not, similarly, incomplete or end-directed. Thus, Aristotle can conclude that insofar as a thing is a first cause of movement, it must not only be active (rather than merely potential), but active in a complete way (and, hence, not undergoing movement).

Aristotle takes this argument to justify his claim that the first cause of a movement must be completely active, and hence that a movement cannot, ultimately, be explained by a movement. The challenge for such a view is to explain how Aristotle can reply to a Platonist, who holds that what produces a movement must do so in virtue of itself undergoing movement. The interpretation sketched above shows how Aristotle might respond. $\mathrm{He}$ argues that movement is a dependent kind of entity: it is an incomplete fulfilment. Because of this, every movement must have an agent that produces the movement in virtue of itself being completely fulfilled. Of course, Plato might disagree with the claim that movement is a dependent entity, a kind of incomplete fulfilment. Alternatively, he might say, with some plausibility, that the kind of movements he had in mind in the Laws were not what Aristotle is calling 'movements'. Plato lists as examples of such movements 'wish, reflection, diligence, counsel, opinion true and false, joy and grief, cheerfulness and fear, love and hate' (897a). 
However, Aristotle does, I think, have an answer to this. Plato himself agrees with Aristotle that every movement requires an agent. That is why Plato thinks that the first movement must be a self-movement (rather than simply being an uncaused movement). What is the justification for this assumption that every movement must have an agent? Aristotle's answer, I want to suggest, is that it is because movement is an incomplete fulfilment that every movement must have an agent. As we have seen, in saying that movement is an incomplete activity, he is saying that it is a dependent entity that cannot itself be causally primary. In other words, it is because movement is in this sense dependent, that it requires an agent.

Aristotle does, then, have something to say to Plato. If Plato disagrees with Aristotle's characterisation of movement, he needs to find a different justification for his assumption that every movement has an agent. So Aristotle's challenge would be this: the very thing that justifies Plato's claim that every movement has an agent (and hence that leads him to say that the first movement must be a self-movement) also justifies the further claim that the first cause of a chain of movements must act as a cause in virtue of being completely in fulfilment, not in virtue of itself undergoing movement.

Moreover, we can now see a further way in which this discussion of self-movers contributes to Aristotle's overall argument. In the earlier chapters of Physics vilI, he argues that every movement has a mover, and claims that a chain of moved movers cannot go on to infinity. The second of these claims is (in these earlier chapters of Physics VIII) simply an assertion, ${ }^{16}$ and the first is based merely on an examination of different cases: he tries to show that something has a mover whether it is moved unnaturally or naturally (and, if naturally, whether it is selfmoved or not). ${ }^{17}$ His account of self-motion in Physics vill.5 provides some theoretical justification for both these claims, for it provides an argument that movement, as an incomplete (and hence dependent) being, must ultimately depend on something that is not similarly incomplete. This implies both that every movement must have a cause, and also that a movement's first cause must be something that is not itself a movement.

I6 As Wardy notes (1990: 89), Aristotle does defend this claim in the second half of Physics Vir.I. My interpretation implies that Wardy is wrong to think that Aristotle needs this Physics vir.I argument to justify what he says in Physics viri.5.

17 Physics viII.4. 


\section{Primary self-movers}

I have claimed that the account of self-movers in Physics virI.5 is framed in such a way as to apply not only to animal self-movers, but also to the first eternally moved thing together with its mover. In support of this claim, I turn now to Aristotle's discussion of what it is for something to be a primary self-mover. I shall argue that Aristotle is here responding to a natural objection to his account of self-motion. The manner in which Aristotle responds to this objection shows, I think, the care he takes in this account of self-movers to confine himself to features that genuine selfmovers share with the first eternally moved thing together with its mover. ${ }^{18}$

The objection to which Aristotle is responding arises because of his view that self-motion is a kind of other-motion: for a thing to move itself is for one part of it to move another part. ${ }^{19}$ The objection is that such an account cannot distinguish between what we would ordinarily call a self-mover and a conjunction of two things, one of which moves the other. Aristotle needs to have something to say about this, in part because animal self-motion is a kind of natural motion. When an animal moves itself from one place to another, the source of this movement is in the animal itself, and hence the movement is natural to the animal and the animal has a nature. Aristotle's account of nature would be undermined if he were forced to concede also that when, say, an animal moves a stick from one place to another, the source of this movement is within the animal+stick, and hence the animal+stick also has a nature (since it has an internal source of change and rest). Aristotle needs some account of how a genuine self-mover constitutes a unity, but the conjunction of such a self-mover with something else that it moves does not.

There are resources within Aristotle's philosophy for answering this. An obvious answer he might give is that the mover, within a self-mover, must be the form of the self-mover. The animal is a self-mover because its mover

I8 Another place where Aristotle is clearly tailoring this account to fit the eternal first motion and its mover is 257 b20-25. Here he is considering the possibility that the two parts of a self-mover might move each other. One of his objections to this is that then it would not be necessary that each part move the other. (The point seems to be that this suggestion only explains why A moves B on the supposition that B moves A, and only explains why B moves A on the supposition that A moves B. It does not explain why A and B are in motion rather than not.) But if we are simply concerned with animal self-motion, it is not obvious why it should be desirable to have an account that presents such motion as necessary. The need to explain the necessity of movement arises when the movement we are trying to account for is eternal celestial movement.

I9 It is important to recognise that a 'part' here need not imply a physically separable part. The mover, for instance, could be the form of the thing. 
(its soul) is its form; the animal+stick is not a self-mover, because its unmoved mover (the animal's soul) is not the form of the animal+stick. This answer would enable him to capture the idea that a self-mover must be a kind of unified whole (since it must have a form, which is its mover), and also to capture the idea that it is really a self-mover, since it implies that what moves the composite is itself accidentally moved..$^{20}$ Given that this is a good Aristotelian reply to our question, it is noteworthy that Aristotle does not give it here. In fact, in this section of Physics viII.5 he says nothing about the mover being the soul or being a kind of form. The reason Aristotle does not give this answer here is, I think, because it would prevent his account of self-movers applying to the combination of the prime mover and what it first moves. The prime mover cannot be the form of the thing it first moves, since then it would itself be moved accidentally, and - as we have seen - Aristotle claims that the ultimate prime mover is not, even accidentally, moved.

Aristotle thus faces a difficult task in attempting to answer our question. On the one hand, he needs to distinguish between a self-moving composite (such as the soul+body) and a composite of one thing's moving another (such as the soul+body+stick). Such a distinction is needed if Aristotle is to avoid attributing an internal source of change and rest, and hence a nature, to all sorts of accidental conjunctions of self-movers with the things they move. On the other hand, Aristotle's account needs to apply not only to a self-moving composite, but also to the conjunction of the first eternally moved thing with its mover. The account of primary self-movers that Aristotle gives in the last part of viII.5 (258a9-b9) is, I shall argue, designed to meet both these constraints.

The account is as follows. If $\mathrm{A}$ (the unmoved mover in the self-mover) moves $B$, and $B$ in its turn moves $C$, then the whole, $A B C$, can be regarded as a self-mover of sorts, but primarily or strictly speaking the self-mover will just be AB. For instance, if the dog's soul moves its body, and its body in turn moves a stick, the primary self-mover will be the combination of the dog's body and soul, in other words, the dog. The primary self-mover, then, will be the unmoved mover together with the first thing that it moves. An animal is a self-mover because it is composed of an unmoved mover (presumably, the animal's soul) together with the first thing moved by that mover. This account allows for the conditions on being a primary selfmover to be satisfied also by the absolutely first mover together with the

${ }^{20}$ Aristotle himself makes this point about animal self-movers at Phys. viII.6, 259bi6-20. For the claim that the soul is the origin of an animal's self-movement, see On the Soul III.9-II. 
thing it first moves, even though (as we have seen) the absolutely first mover cannot be the form or soul of the thing it first moves, since it is not accidentally moved by the movement it causes.

For this account to avoid obvious counterexamples, it is important that the kind of self-movement Aristotle has in mind here is selflocomotion. He says that this is, properly speaking, the only selfmovement (253aI4-I5, 26Ia23-25). So if a hot thing, without itself undergoing change, causes something else to become hot, the hot thing and the thing it heats do not, together, satisfy these conditions on being a self-mover. ${ }^{2 I}$ If one assumes (in accordance with what Aristotle himself asserts) that, at least in the sublunary realm, every origin of motion is a self-motion and the origin of the self-motion is an unmoved mover, then we can always trace a chain of moved movers back to an unmoved mover. The first of these moved movers, together with the unmoved mover will constitute a self-mover. Aristotle holds that, in the sublunary realm, this will be an animal.

Of course, one obvious question about this account is what it can say about the unity of $\mathrm{B}$ and of $\mathrm{C}$ (the first thing that is moved by the unmoved mover, and whatever is in its turn moved by that first thing). What makes $\mathrm{B}$ and $\mathrm{C}$ two distinct things, thus justifying the conclusion that $\mathrm{B}$, rather than B plus C, is the first thing moved? Suppose B is itself composed of parts (as Aristotle has argued it must be, given that it is moved). What justifies the claim that $\mathrm{B}$, as opposed to one of its parts, is the first thing moved?

As Aristotle points out, these questions can be pressed in such a way as to suggest that there is no first thing moved (and hence no primary selfmover). According to Aristotle, any thing that is moved is infinitely divisible: it has parts, which in turn have other parts, and so on ad infinitum. ${ }^{22}$ Moreover, its movement depends on the movement of its parts (at least, in the sense that the movement of the parts is a necessary condition of the movement of the whole). This raises a problem for Aristotle, since it suggests that there may be no first thing moved: any putative first thing moved by the unmoved mover will in fact only be

${ }^{21}$ It is less obvious how Aristotle can avoid allowing that this Physics VIII.5 account applies to the conjunction of a magnet and the iron it attracts.

${ }^{22}$ He argues for this in Physics vi.4, and he reminds us of this claim at Phys. viII.5, 257a33-bi, just before giving his argument that a self-mover does not move itself as a whole. The relevance of lines 257a33-br in their immediate context is not at all obvious. However, the point Aristotle makes here about infinite divisibility is important for understanding the aporia (at the end of Physics viri.5) about the primary thing moved. 
moved because certain other things (its parts) are themselves moved by the unmoved mover. Thus, any self-mover, $\mathrm{AB}$, will have a more primary selfmover that is its part: 'AB will not be what is primarily moved by itself, since when something is taken away from $\mathrm{AB}$, the remainder will continue to move itself (258a30-32).

In raising this worry, Aristotle is taking up, and responding to, an argument that he himself gave in Physics vir.I. It is an argument for the conclusion that every moved thing is moved by something. Although of course he still agrees with this conclusion in Physics ViII, he realises that he cannot endorse the argument of Physics Vir.I. ${ }^{23}$ That argument starts out from the claim that anything that is moved is infinitely divisible. This is taken to imply that its movement depends on its parts, and hence on something that is distinct from it (since a thing is distinct from its parts). Since the parts are divisible, their movement will depend on the movement of their parts, and so on ad infinitum. In Physics vir.I Aristotle concludes from this that a moved thing must be moved by something that is distinct from it.

In Physics ViII.5, Aristotle sees that he cannot endorse this argument, since, if it were successful, it would imply that there was no first thing moved. Every moved thing would depend for its movement on the other, prior, moved things that were its parts. This is a conclusion that Aristotle cannot accept, since it would undermine his argument that a chain of moved movers originates in a first mover together with a first thing moved by that mover.

His response, in Physics vili.5, is to claim that the moved thing is potentially, but not actually, divided: 'so that if it is divided it will not continue in possession of the same nature' $(258 \mathrm{~b} 2-3)$. Although anything that is moved can be divided into parts, this does not imply that a thing's movement is causally dependent on the movement of its parts. In fact, its parts may only move in virtue of being parts of the whole. A sign that this is so is that many self-movers no longer move themselves when divided. Hence, the fact that the moved thing is infinitely divisible does not undermine the claim that there are primary self-movers. A primary selfmover will be divisible into parts, but these parts will not be things that would, if separated from the primary self-mover, be self-movers in their own right.

${ }^{23}$ This, of course, raises interesting questions about the role of Physics vin in the Physics as a whole. It suggests that Aristotle did have Physics viI in mind when he wrote Physics viII, but that he did not intend the two books to be part of a single work (since he took some of his arguments in viri to supersede those he had given in VII). 
As an account of animal self-movers, this response is not wholly successful. As Aristotle himself remarks elsewhere, some animals can be cut in two in such a way that their parts continue to move themselves. Does Aristotle have to deny that these are primary self-movers? ${ }^{24}$ Moreover, even in the case of animals that cannot be cut in half and continue to move, there are usually parts one can remove that would still allow what remains of the animal to move itself. Is Aristotle committed to the claim that it is not strictly speaking the animal that is the self-mover, but the animal minus its hair and teeth and ... ? Finally, it is not clear that even this subtracting procedure will always arrive at a definite first mover. It might turn out that the animal would remain a self-mover without part A or without part B, but not without both. In such a case the animal minus part $A$ and the animal minus part $B$ would both seem to have equal claim to be the primary selfmover.

Aristotle does not consider any of these problems here. I suspect part of the reason for this is that in this context he is not, primarily, interested in giving a full account of animal self-motion. Instead, he defends the claim that there can be a primary thing moved, because he will need to assume this claim in the account he goes on to give of the relation between the first eternal motion and its mover. In giving that account, he emphasises that there is one unified, continuous first motion. It is because of the unity and continuity of this first motion that it requires both a single subject and also a single absolutely first mover: 'if motion is continuous, it is one, and it is one only if its mover is one and the thing that undergoes the motion is one' (259ar7-19). Aristotle's argument thus relies on there being not only a single continuous motion, but also a single unified subject for such a motion. If such a subject is to have the right kind of unity, its movement cannot be causally dependent on the movement of its parts. This is why it is so important for Aristotle, in Physics virI.5, to explain what was wrong with his earlier argument in Physics vir.I.

I have claimed that Aristotle's account of self-movers in Physics VIII.5 is best understood when we consider its role in his more general argument. $\mathrm{He}$ is not attempting here to give a full account of what is involved in an animal's moving itself. Instead, he gives a highly abstract argument that appeals to his earlier discussion of the ontological status of motion. This account serves several purposes. It presents a challenge to Plato's alternative

${ }^{24}$ Perhaps he would not be worried by this conclusion. At Progression of Animals 707a24-b4, he implies that an animal that is divisible in this way is like a single body that contains within it many living beings (see also Juv. 468b9-15). 
view of the origin of movement. More positively, it provides an argument that movement must, ultimately, be caused by something that is not itself a movement. Finally, by giving this account of self-motion, Aristotle shows that it is possible, at least at a certain level of abstraction, for there to be a single account that applies both to animal self-movers and also to the first eternal movement together with its mover. Insofar as the account is successful, it thus provides some basis for the view that physics, the study of motion, is a single unified science. 